\title{
Aplicação do gerenciamento de riscos no processo de desenvolvimento de produtos nas empresas de autopeças
}

\author{
Carlos Eduardo Sanches da Silva ${ }^{\mathrm{a}, *}$, Carlos Henrique Pereira Mello ${ }^{\mathrm{b}}$, \\ Natália Fernanda Gabriela Siqueira ${ }^{c}$, Henrique Andrade Godoy ${ }^{\mathrm{d}}$, \\ Eduardo Gomes Salgado ${ }^{\mathrm{e}}$ \\ a,*sanches@unifei.edu.br, UNIFEl, Brasil \\ bcarlos.mello@unifei.edu.br, UNIFEl, Brasil \\ cnatalia.siqueira@novelis.com, UNIFEl, Brasil \\ dhenriqueagodoy@yahoo.com.br, UNIFEl, Brasil \\ eegsalgado@yahoo.com.br, UNIFAL, Brasil
}

\begin{abstract}
Resumo
Esta pesquisa analisa a incorporação do gerenciamento de riscos no processo de desenvolvimento de produtos (PDP) nas empresas de autopeças, fundamentado no Advanced Product Quality Planning (APQP), enfatiza as entregas do projeto de desenvolvimento preconizadas pelo Production Parts Approval Process (PAPP) e realiza uma revisão bibliográfica estabelecendo os fundamentos teóricos para seu desenvolvimento. 0 método de pesquisa utilizado foi a pesquisa-ação, cujos dados foram coletados por meio de análise documental, entrevistas e observações dos pesquisadores. A incorporação do gerenciamento de riscos no PDP contribui para o processo decisório, principalmente nas etapas de análise de riscos qualitativos e de planejamento de respostas aos riscos, fornecendo maior precisão quanto aos prazos e à identificação das atividades críticas. Os fatores que se destacaram para se obter a precisão dos resultados são: a formação da equipe; a discussão coletiva dos prazos fornecidos, tendo como resultado o comprometimento; o papel do gerente do projeto, propiciando o feedback entre os participantes, e a existência de evidências objetivas do apoio da alta administração. Conclui-se que a formação da equipe influencia no gerenciamento de riscos, sendo preponderante na percepção dos riscos a formação educacional.
\end{abstract}

Palavras-chave

Gerenciamento de projetos. Gerenciamento de riscos. Desenvolvimento de produtos. APQP. PAPP.

\section{Introdução}

Esta pesquisa fundamenta-se na aplicação dos estudos de Baskerville e Stage (1996), que utilizam a análise de riscos no desenvolvimento de protótipos, e de Galway (2004), que questiona o gerenciamento de riscos. Existe uma grande concentração de pesquisas que abordam o tema análise de risco nos projetos realizados pela National Aeronautics and Space Administration (NASA), como Brothers e Fayssal (2002) e Mahadevan, Smith e Zang (2003). A importância do gerenciamento de riscos para a NASA culminou na norma ISO 17666: 2003 (Space systems - Risk management).

Desde a década de 1980, identifica-se na literatura a crescente preocupação com o gerenciamento de riscos nos projetos (ARTTO, 1997). Evidências da relevância do tema podem ser identificadas nas pesquisas de:

- Raz e Michael (1999), que concluem que informalmente os riscos inerentes ao PDP são identificados, mas, para a sistematização da análise de riscos, faz-se necessário um processo formal que permita auferir ao projeto uma maior probabilidade de sucesso;

- Smith e Merritt (2002), que identificaram que o gerenciamento de riscos é pouco utilizado no Processo de Desenvolvimento de Produtos (PDP);

- Voetsch (2004), que, através de uma survey em várias empresas mundiais, pesquisou como é realizado o gerenciamento de riscos e concluiu que o uso de ferramentas quantitativas é baixo 
$(13,5 \%)$, que grande parte das ações é focada na identificação dos riscos $(87,4 \%)$ e que existe um gap entre o domínio teórico da gestão de riscos e sua aplicação prática;

- Galway (2004) realizou uma vasta revisão bibliográfica e entrevistas, evidenciando que a evolução dos tipos de projetos e seus desafios estão se modificando significativamente, exigindo-se, assim, a aplicação do gerenciamento de riscos; a aplicação do gerenciamento de riscos faz-se mais presente em projetos estratégicos, de natureza competitiva, o que restringe a socialização das experiências e lições aprendidas (devido aos dados e informações sigilosos); é difícil atribuir exclusivamente o sucesso ou o fracasso de um projeto ao gerenciamento de riscos, mas este sempre é citado como fator relevante.

- Maytorena et al. (2007), que buscaram avaliar até que ponto a experiência dos gerentes de projetos é determinante para identificar os riscos do projeto. Eles entrevistaram 51 gerentes de projetos e utilizaram a Expected Utility Theory para analisar os dados. Os resultados sugerem que a experiência dos gerentes de projeto é muito menos significante que o estilo de feedback na busca de informações, o nível de educação formal e o treinamento em gerenciamento de riscos. Quem possui mais experiência em gerenciamento de projetos tende a não buscar informações para a etapa de identificação de riscos. Sua pesquisa demonstra empiricamente que o excesso de confiança gerado pela experiência é contraprodutivo na identificação de riscos, podendo encorajar a mentalidade da elaboração de um chek-list ou até mesmo simplesmente copiar a análise de risco de outros projetos similares.

No contexto das pesquisas descritas, identifica-se a presente pesquisa, abordando o gerenciamento de riscos aplicado ao processo de desenvolvimento de produtos, que é uma lacuna na base de conhecimentos, como identificaram Smith e Merritt (2002).

O setor automobilístico foi definido como objeto de estudo por possuir a norma ISO TS 16949, que estabelece um referencial mínimo para o PDP, além de agregar uma proposta para o processo de desenvolvimento de produtos preconizado pelo Advanced Product Quality Planning (APQP) e evidenciado pelo Production Parts Approval Process (PAPP).

Esta pesquisa tem como objetivo avaliar a aplicação do gerenciamento de riscos no processo de desenvolvimento de produtos de empresas do setor de autopeças.

Desenvolveu-se uma fundamentação teórica acerca do gerenciamento de projetos com ênfase no gerenciamento de riscos, estabeleceu-se o planejamento da pesquisa e selecionou-se a empresa objeto de estudo. Por meio de uma pesquisa-ação, aplicou-se o gerenciamento de riscos no processo de desenvolvimento de produtos, coletando e analisado os dados que forneceram os subsídios para as conclusões e recomendações.

\section{Gerenciamento de projetos e a incorporação dos riscos}

0 Project Management Body of Knowledge PMBOK (PMI, 2004) define 'projeto' como um esforço temporário empreendido para criar um produto, um serviço ou um resultado exclusivo. Assim, os projetos se caracterizam por: temporalidade (início e fim definidos), resultado (produto único) e elaboração progressiva (realização de etapas de maneira incremental).

Segundo o PMBOK (2004), o gerenciamento de um projeto é composto pelas seguintes áreas de conhecimento: integração, escopo, tempo, custo, qualidade, recursos humanos, comunicação, aquisição e riscos. A presente pesquisa delimitou seu estudo na área de gerenciamento de riscos.

Para Schuyler (2001), 'risco' é o efeito acumulativo da probabilidade de incerteza que pode afetar positivamente (oportunidade) ou negativamente (ameaça) o projeto. Galway (2004), em vez de buscar respostas para a pergunta " 0 que é uma boa análise de riscos?", buscou responder o que os usuários do projeto esperam do gerenciamento de riscos. A resposta foi óbvia: precisão (análise qualitativa - probabilidade) e auxílio no processo decisório.

O gerenciamento de um processo, diferentemente do gerenciamento de um projeto, trata de atividades que se repetem ao longo do tempo, de modo que pode ser estudado baseando-se em históricos. Entretanto, em projetos, a base de estudos possui uma quantidade bem menor de fatos e dados, se comparado aos processos, estando, desta maneira, exposto a vários riscos desconhecidos (ALENCAR; SCHMITZ, 2006).

Rovai (2005) afirma, com certa dose de exagero, que muitos projetos no Brasil, senão a quase totalidade, são desenvolvidos sem que haja o adequado uso de metodologias e/ou modelos de gerenciamento de risco, o que tem causado inúmeras perdas financeiras e de recursos com intensidade e impacto variáveis, porém significativos. Nakashima e Carvalho (2004) reforçam que nenhum especialista é capaz de prever todas as possibilidades. Deste modo, buscar informações em fontes seguras, externas ao grupo de gerenciamento, é fundamental na fase de identificação de riscos. 
0 Quadro 1 descreve algumas abordagens do gerenciamento de riscos descritas na pesquisa de Ferreira e Ogliari (2005), sendo acrescentadas as abordagens de Boehm e Bose (1994) e Kontio (1996).

A análise do Quadro 1 permite identificar similaridades nos modelos descritos que prescrevem duas marco-etapas: planejamento - P (estabelecer metas, planejamento, identificação, análise, decidir o que deve ser realizado) e controle - C (acompanhamento, avaliação, resposta, controle de riscos, lições aprendidas).

Lyons e Skitmore (2004) identificaram em uma survey que o gerenciamento de riscos é deficiente na monitoração e no controle, sendo a maioria dos esforços alocados nas demais etapas de planejamento. Pode-se identificar que os modelos citados detalham mais as etapas de planejamento em relação ao controle, além do fato de que, no projeto, o planejamento normalmente implica no uso de menos recursos se comparado ao controle, que ocorre concomitante com as atividades de execução do projeto (concorrência pelos recursos).

Rovai (2005) identifica que os modelos propostos para o gerenciamento de riscos são focados no "que deve ser feito" e não no "como". Ele propõe um modelo de análise de riscos constituído de camadas: estratégias, processos, competências, cultura, aplicação e desempenho. Para cada camada, foram apresentadas as técnicas e como elas poderiam ser aplicadas. 0 Autor comparou seu modelo com o proposto pelo PMBOK e obteve como resultados a mesma precisão, a inferioridade em relação à flexibilidade e à atratividade, e a superioridade em relação a consistência, facilidade, resultados, maturidade e viabilidade.

A diferença básica dos modelos é o nível de detalhamento de cada etapa. Verifica-se que alguns modelos precificam diretrizes da alta administração em relação à análise de riscos, buscam evidenciar o comprometimento da alta administração e a incorporação de aspectos estratégicos.

Comparando os modelos, identificam-se vantagens no modelo do PMl (2000), como: preocupação com o planejamento, abordagem qualitativa e quantitativa de riscos, ampla aceitação, flexibilidade e precisão. Assim, o presente trabalho buscou se basear no modelo do PMl descrito no Quadro 2.

Muitos autores citam as vantagens de se incorporar no projeto a análise de riscos, com destaque para a pesquisa de Galway (2004). Sua pesquisa buscou inquirir vários profissionais da comunidade de gerenciamento de riscos (acadêmicos, empresas de consultoria e softwares que atuam na área de gerenciamento de riscos e profissionais de projetos das organizações) acerca da relevância do gerenciamento de riscos. A resposta unânime foi que o gerenciamento de riscos merece ser contemplado nos projetos, pois é claramente útil. Porém, no decorrer das entrevistas, surgiram informações de que o gerenciamento de riscos não é bem entendido e integrado ao projeto; os gerentes de projeto afirmaram que a análise de riscos normalmente é realizada por ser exigência do

Quadro 1. Modelos de gerenciamento de riscos.

\begin{tabular}{|c|c|c|c|c|c|c|}
\hline Autores & \multicolumn{6}{|c|}{ Processo de gerenciamento de riscos } \\
\hline $\begin{array}{l}\text { Boehm e Bose } \\
\text { (1994) }\end{array}$ & $\begin{array}{c}\text { Definição } \\
\text { obrigatória do } \\
\text { gerenciamento } \\
\text { de riscos (P) }\end{array}$ & $\begin{array}{l}\text { Rever metas } \\
\text { (P) }\end{array}$ & $\begin{array}{l}\text { Identificar } \\
\text { riscos }(\mathrm{P})\end{array}$ & $\begin{array}{c}\text { Analisar riscos } \\
\text { (P) }\end{array}$ & $\begin{array}{l}\text { Planejar o } \\
\text { controle dos } \\
\text { riscos }(\mathrm{P})\end{array}$ & $\begin{array}{l}\text { Controlar e } \\
\text { monitorar os } \\
\text { riscos (C) }\end{array}$ \\
\hline $\begin{array}{l}\text { Kontio } \\
(1996)\end{array}$ & $\begin{array}{l}\text { Rever as metas } \\
\text { definidas }(\mathrm{P})\end{array}$ & $\begin{array}{l}\text { ldentificação } \\
\text { dos riscos (P) }\end{array}$ & $\begin{array}{c}\text { Analisar os } \\
\text { riscos (P) }\end{array}$ & $\begin{array}{c}\text { Planejar o } \\
\text { controle dos } \\
\text { riscos }(\mathrm{P})\end{array}$ & $\begin{array}{l}\text { Controlar os } \\
\text { riscos }(\mathrm{C})\end{array}$ & - \\
\hline $\begin{array}{l}\text { Kezner } \\
(1998)\end{array}$ & $\begin{array}{l}\text { ldentificação } \\
\text { dos riscos (P) }\end{array}$ & $\begin{array}{l}\text { Qualificação } \\
\text { dos riscos (P) }\end{array}$ & $\begin{array}{l}\text { Resposta a } \\
\text { riscos }(\mathrm{P})\end{array}$ & $\begin{array}{l}\text { Controle dos } \\
\text { riscos/lições } \\
\text { aprendidas (C) }\end{array}$ & - & - \\
\hline $\begin{array}{c}\text { PMl } \\
(2000)\end{array}$ & $\begin{array}{c}\text { Planejamento } \\
\text { gerenciamento } \\
\text { de riscos }(\mathrm{P})\end{array}$ & $\begin{array}{l}\text { Identificação de } \\
\text { riscos (P) }\end{array}$ & $\begin{array}{c}\text { Análise } \\
\text { qualitativa de } \\
\text { riscos }(\mathrm{P})\end{array}$ & $\begin{array}{c}\text { Análise } \\
\text { quantitativa } \\
\text { de riscos }(\mathrm{P})\end{array}$ & $\begin{array}{l}\text { Planejamento } \\
\text { das respostas de } \\
\text { riscos (P) }\end{array}$ & $\begin{array}{l}\text { Monitoração e } \\
\text { controle de } \\
\text { riscos (C) }\end{array}$ \\
\hline $\begin{array}{c}\text { Smith e Merrit } \\
\text { (2002) }\end{array}$ & $\begin{array}{l}\text { ldentificação } \\
\text { dos riscos (P) }\end{array}$ & $\begin{array}{l}\text { Análise dos } \\
\text { riscos (P) }\end{array}$ & $\begin{array}{c}\text { Priorização dos } \\
\text { riscos e mapa } \\
\text { de riscos }(\mathrm{P})\end{array}$ & $\begin{array}{l}\text { Redução dos } \\
\text { riscos (C) }\end{array}$ & $\begin{array}{l}\text { Monitoração } \\
\text { dos riscos (C) }\end{array}$ & - \\
\hline $\begin{array}{c}\text { Alencar e } \\
\text { Schmitz } \\
(2006)\end{array}$ & $\begin{array}{l}\text { ldentificação } \\
\text { dos fatores de } \\
\text { risco (P) }\end{array}$ & $\begin{array}{c}\text { Avaliação de } \\
\text { impactos e } \\
\text { probalidades (P) }\end{array}$ & $\begin{array}{c}\text { Elaboração } \\
\text { de planos de } \\
\text { contenção e } \\
\text { contingência (P) }\end{array}$ & $\begin{array}{l}\text { Redefinição } \\
\text { do plano do } \\
\text { projeto }(\mathrm{P})\end{array}$ & $\begin{array}{l}\text { Monitoramento } \\
\text { dos fatores de } \\
\text { risco (C) }\end{array}$ & $\begin{array}{l}\text { Execução das } \\
\text { atividades } \\
\text { contigenciadas } \\
\text { (C) }\end{array}$ \\
\hline
\end{tabular}

Fonte: adaptado de Ferreira e Ogliari (2005). 
Quadro 2. Modelo de gerenciamento de riscos proposto pelo PMI.

\begin{tabular}{|c|c|c|}
\hline Etapa & Descrição & Ferramentas \\
\hline $\begin{array}{l}\text { 1. Planejamento } \\
\text { do gerenciamento } \\
\text { de riscos }\end{array}$ & $\begin{array}{l}\text { Como abordar, planejar e executar } \\
\text { as atividades de gerenciamento de } \\
\text { riscos de um projeto. }\end{array}$ & Análises e reuniões de planejamento. \\
\hline $\begin{array}{l}\text { 2. Identificação } \\
\text { de riscos }\end{array}$ & $\begin{array}{l}\text { Determinação dos riscos que podem } \\
\text { afetar o projeto e documentação } \\
\text { de suas características. }\end{array}$ & $\begin{array}{l}\text { Revisões da documentação; técnicas de coleta de informações: } \\
\text { Brainstorming, técnica Delphi, entrevistas, identificação da } \\
\text { causa-raiz, análise dos pontos fortes e fracos, oportunidades } \\
\text { e ameaças (SWOT); análise da lista de verificação; análise das } \\
\text { premissas; técnicas com diagramas: causa e efeito; sistema } \\
\text { ou fluxogramas; influência. }\end{array}$ \\
\hline $\begin{array}{l}\text { 3. Análise } \\
\text { qualitativa } \\
\text { de riscos }\end{array}$ & $\begin{array}{l}\text { Priorização dos riscos para análise } \\
\text { ou ação adicional subsequente } \\
\text { através de avaliação e combinação } \\
\text { de sua probabilidade de ocorrência } \\
\text { e impacto. }\end{array}$ & $\begin{array}{l}\text { Avaliação de probabilidade e impacto de riscos; matriz de } \\
\text { probabilidade e impacto; avaliação da qualidade dos dados } \\
\text { sobre riscos; categorização de riscos; avaliação da urgência } \\
\text { do risco. }\end{array}$ \\
\hline $\begin{array}{l}\text { 4. Análise } \\
\text { quantitativa } \\
\text { de riscos }\end{array}$ & $\begin{array}{l}\text { Análise numérica do efeito dos } \\
\text { riscos identificados nos objetivos } \\
\text { gerais do projeto. }\end{array}$ & $\begin{array}{l}\text { Técnicas de representação e coleta de dados: entrevistas; } \\
\text { distribuições de probabilidades; opinião especializada; análise } \\
\text { quantitativa de riscos e técnicas de modelagem: análise de } \\
\text { sensibilidade, análise do valor monetário esperado, análise da } \\
\text { árvore de decisão, modelagem e simulação. }\end{array}$ \\
\hline $\begin{array}{l}\text { 5. Planejamento } \\
\text { das respostas } \\
\text { a riscos }\end{array}$ & $\begin{array}{l}\text { Desenvolvimento de opções e ações } \\
\text { para aumentar as oportunidades e } \\
\text { reduzir as ameaças aos objetivos } \\
\text { do projeto. }\end{array}$ & $\begin{array}{l}\text { Estratégias para riscos negativos ou ameaças: prevenir, } \\
\text { transferir, mitigar; estratégias para riscos positivos ou } \\
\text { oportunidades: explorar; compartilhar; melhorar; estratégia } \\
\text { para ameaças e oportunidades: aceitação; estratégia para } \\
\text { respostas contingenciadas. }\end{array}$ \\
\hline $\begin{array}{l}\text { 6. Monitoração e } \\
\text { controle de } \\
\text { riscos }\end{array}$ & $\begin{array}{l}\text { Acompanhamento dos riscos } \\
\text { identificados, monitoramento dos } \\
\text { riscos residuais, identificação dos } \\
\text { novos riscos, execução de planos } \\
\text { de respostas a riscos e avaliação da } \\
\text { sua eficácia durante todo o ciclo } \\
\text { de vida do projeto. }\end{array}$ & $\begin{array}{l}\text { Reavaliação de riscos; auditorias de riscos; análise das } \\
\text { tendências e da variação; medição do desempenho técnico; } \\
\text { análise das reservas; reuniões de andamento. }\end{array}$ \\
\hline
\end{tabular}

cliente (caso específico dos projetos realizados para o governo americano). 0 autor conclui que a utilidade do gerenciamento de riscos é anedótica e que os principais problemas técnicos são: definir o nível das atividades do projeto, definir as probabilidades, desprezar as correlações entre as atividades, ignorar os efeitos das "habilidades" do gerente de projeto; conclui, ainda, que os dados nunca são suficientes.

Segundo Albeny (2007), o gerenciamento de riscos ainda não pode ser considerado uma área de conhecimento consolidado, apesar de haverinúmeros livros, artigos e guias práticos que abordam o tema. 0 autor afirma que a importância do gerenciamento de riscos tem ganhado reconhecimento e vem sendo discutido cada vez mais entre os estudiosos. Contudo, ainda há um grande número de gerentes de projetos que não abordam o tema com a seriedade requerida.

Especificamente tratando de riscos no processo de desenvolvimento de produtos, Segismundo e Miguel (2008) levantaram em um estudo que a quantidade de publicações abordando o tema é ainda muito pequena. Em vista disso, o presente trabalho visa contribuir para o aumento de estudos acerca da aplicação do gerenciamento de riscos no processo de desenvolvimento de produtos, com o intuito de reduzir esta lacuna na base de conhecimento.

Blau et al. (2000) consideram como riscos no processo de desenvolvimento de produtos: a possibilidade de este não vir a atender os requisitos de forma satisfatória, o processo de priorização de produtos dentro de um portfólio e, também, os riscos relacionados aos custos e prazos no processo de desenvolvimento.

Partindo dos mesmos tipos de riscos, mas os chamando de incertezas, Huchzermeier e Loch (2001) desenvolveram estudos que analisaram como estes fatores influenciam o grau de flexibilidade gerencial nos processos de desenvolvimento de produto.

Chamberlain e Modarres (2005), por sua vez, concentraram sua atenção nos riscos que dizem respeito aos aspectos de especificações técnicas do produto, analisando os riscos de incêndio em compressores de veículos movidos a gás e 
determinando a sensibilidade dos resultados a variações nas taxas de falhas dos componentes.

Abordando o tema sob outro enfoque, Trammell, Lorenzo e Davis (2004) propuseram um novo método para análise de riscos no desenvolvimento de produtos, após constatarem que os métodos até então existentes não cobriam todas as vertentes dos riscos. 0 resultado desse trabalho é a proposta da combinação de ferramentas e métodos para se garantir melhor eficácia no levantamento dos riscos bem como na priorização dos mesmos. Também tratando o tema sob a ótica dos métodos para se lidar com riscos e abordando suas implicações gerenciais, Miller e Lessard (2001) propõem um processo para se enfrentarem os riscos por meio do reconhecimento, da adaptação e da realização das opções reais que a literatura aborda.

Por fim, Brighenti Jr. (2005) conclui seu trabalho afirmando que, no processo de desenvolvimento de sistemas, é necessário adotar uma metodologia sistemática e disciplinada para gerenciar os riscos, para que se reduza a ocorrência de eventos inesperados.

Para a aplicação do gerenciamento de riscos propostos no PMBOK (PMI, 2004) no processo de desenvolvimento de produtos de empresas certificadas pela norma ISO TS 16949, faz-se necessário estabelecer alguns fundamentos, discutidos a seguir.

\section{0 processo de desenvolvimento de produtos da indústria automobilística segundo a ISO TS 16949}

0 setor automobilístico é responsável por várias evoluções de gestão, como a produção em massa, o Just in Time e padrões normativos de sistema da qualidade. Devido ao seu elevado alcance econômico e a padrões normativos específicos, o setor busca obter vantagem competitiva em sua cadeia de valor por meio da implementação de padrões normativos para o relacionamento com seus fornecedores.

0 esforço inicial para o estabelecimento desses padrões normativos culminou em normas específicas, como a VDA 06 alemã (Volkswagen e BMW), a AVSQ italiana (Fiat e lveco), WAQF francesa (Renault e Peugeot) e a QS 9000 americana (General Motors, Ford e Daimer Chysler). Para uniformizar estas normas, foi criada pelas empresas do setor automobilístico - a Automotive Industries Action Group (AlAG) - a especificação técnica ISO TS 16949. Lançada em 1999, a ISO TS 16949 tem como objetivo harmonizar os sistemas da qualidade de montadoras, facilitando e simplificando a comunicação com a base de fornecedores (1QA, 1999).
Vale destacar que as montadoras possuem requisitos específicos que não puderam ser uniformizados pela ISO TS 16949, existindo, assim, normas específicas complementares.

As montadoras recomendam e estimulam 0 uso de várias ferramentas para o desenvolvimento de projeto e a melhoria contínua do processo de desenvolvimento de produtos. Uma das mais conhecidas é o Planejamento Avançado da Qualidade do Produto (APQP), desenvolvido pelo AIAG (VIEIRA, 2007).

Segundo o IQA (1997), o APQP é um método estruturado de trabalho em equipe para definir e estabelecer as etapas necessárias para assegurar que o produto atende os requisitos de satisfação do cliente. Busca, ainda, facilitar a comunicação entre os envolvidos, assegurando o cumprimento de todas as atividades dentro dos prazos estabelecidos, minimizando os custos associados e mitigando os riscos de não conformidades no lançamento do produto.

Todas as atividades descritas no manual do APQP estão discriminadas em sequência lógica, segundo a qual a saída de uma fase é a entrada da próxima.

0 projeto é desmembrado em porções menores gerenciáveis, conhecidas como pacotes de trabalho que, por sua vez, geram entregas (físicas everificáveis). Adotando como modelo de desenvolvimento de produtos o APQP, as entregas mínimas previstas pelo cliente são os documentos preconizados pelo Production Parts Approval Process (PAPP), também conhecido como Processo de Aprovação de Peças de Produção. O PAPP determina que todos os requisitos de desenho e especificação do produto do cliente sejam adequadamente compreendidos pelo fornecedor e verifica se o processo tem potencial para produzir produtos que atendam tais requisitos durante um lote efetivo de produção (1QA, 1999).

0 manual do PAPP faz parte do conjunto de requisitos e manuais de referência do Sistema da Qualidade ISO TS 16949. Os registros que formam o PAPP são coletados ao longo das etapas cronológicas do PDP. Assim, no presente trabalho, considera-se que as entregas realizadas ao longo do processo de desenvolvimento de produtos encontram-se evidenciadas pelo PAPP.

Vale ressaltar que o processo de desenvolvimento de produtos, devido a sua complexidade e unicidade, pode ter atividades diferentes, conforme as respectivas entregas. Mas, com certeza, as entregas mínimas são as prescritas pelo PAPP, sendo assim entregas comuns a todas as empresas certificadas pela ISO TS 16949. 


\section{Método de pesquisa}

Dado o objetivo da pesquisa, utilizou-se a pesquisa-ação como método, por buscar solucionar um problema empresarial com uma abordagem científica. Neste tipo de pesquisa, ocorre, simultaneamente, a produção e o uso de conhecimentos. 0 Quadro 3 apresenta o planejamento empregado para a coleta de dados.

Thiollent (1998) define a pesquisa-ação como um método de pesquisa participante que consiste em acoplar pesquisa e ação em um processo no qual os atores implicados participam, junto com os pesquisadores, para chegarem interativamente a elucidar a realidade em que estão inseridos, identificando problemas coletivos, buscando e experimentando soluções em situação real.

Por ser interativa, a pesquisa-ação exige que os pesquisadores e participantes encontrem palavras adequadas para descrever, questionar ou criticar o que estão observando. Assim, o domínio da linguagem verbal e corporal é significativo para interpretar o que as pessoas estão dizendo ou querem fazer em termos de ação (THIOLLENT, 1998). Neste sentido, estabelece-se o planejamento para coleta de dados (Quadro 3) a ser utilizado ao longo da implementação do gerenciamento de riscos (GR), segundo as etapas preconizadas pelo PMBOK (Quadro 2). As técnicas de coleta de dados empregadas foram a entrevista (E), as observações participantes (0) e os registros ( $R$ ).

\section{Descrição da aplicação da análise de riscos no processo de desenvolvimento de produtos e análise dos dados}

Os critérios utilizados para escolha da empresa objeto do presente estudo foram: certificação ISO TS 16949, assegurando assim a obrigatoriedade de elaboração do PAPP; interesse em aplicar o gerenciamento de riscos em seu processo de

Quadro 3. Planejamento da coleta de dados.

\begin{tabular}{|c|c|c|c|c|c|c|c|}
\hline \multirow{2}{*}{\multicolumn{3}{|c|}{ Pesquisa }} & \multirow{2}{*}{ Conclusões } & \multirow{2}{*}{ Questões } & \multicolumn{3}{|c|}{ Dados } \\
\hline & & & & & \multirow{2}{*}{$\begin{array}{l}\mathrm{E} \\
-\end{array}$} & \multirow{2}{*}{0} & \multirow{2}{*}{$\begin{array}{l}\mathrm{R} \\
\mathrm{X}\end{array}$} \\
\hline \multicolumn{3}{|c|}{$\begin{array}{c}\text { Nakashima e } \\
\text { Carvalho (2004) }\end{array}$} & $\begin{array}{l}\text { Buscar informações em fontes } \\
\text { seguras, externas ao grupo. }\end{array}$ & $\begin{array}{l}\text { Onde e como foram obtidas as } \\
\text { informações para identificação de riscos? }\end{array}$ & & & \\
\hline \multirow{4}{*}{ 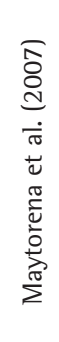 } & \multirow{4}{*}{ 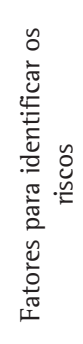 } & \multirow{2}{*}{ 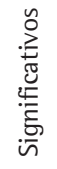 } & $\begin{array}{l}\text { Estilo de feedback na busca de } \\
\text { informações. }\end{array}$ & $\begin{array}{l}\text { Como foi a identificação dos riscos? } \\
\text { Qual influência no GR? }\end{array}$ & $X$ & $X$ & $X$ \\
\hline & & & Nivel de educação formal. & $\begin{array}{l}\text { Qual o nível educacional dos envolvidos? } \\
\text { Qual influência no GR? }\end{array}$ & $X$ & - & $X$ \\
\hline & & \multirow{2}{*}{ 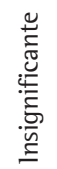 } & $\begin{array}{l}\text { Treinamento em gerenciamento } \\
\text { de risco. }\end{array}$ & $\begin{array}{l}\text { Quais as capacitações em GR? Qual } \\
\text { influência no GR? }\end{array}$ & $X$ & - & $X$ \\
\hline & & & $\begin{array}{l}\text { Experiência do gerente de } \\
\text { projeto. }\end{array}$ & $\begin{array}{l}\text { Qual o nível de experiência do gerente } \\
\text { do projeto? Qual influência no GR? }\end{array}$ & $X$ & $X$ & $X$ \\
\hline \multirow{2}{*}{\multicolumn{3}{|c|}{$\begin{array}{l}\text { Lyons e Skitmore } \\
\qquad(2004)\end{array}$}} & $\begin{array}{l}\text { Gerenciamento de riscos é } \\
\text { deficiente na monitoração e } \\
\text { controle. }\end{array}$ & \multirow{2}{*}{$\begin{array}{l}\text { Como foram implementadas as etapas } \\
\text { do GR? }\end{array}$} & - & $X$ & $X$ \\
\hline & & & $\begin{array}{l}\text { Maioria dos esforços alocados } \\
\text { nas etapas de planejamento. }\end{array}$ & & - & $X$ & $X$ \\
\hline \multicolumn{3}{|c|}{$\begin{array}{l}\text { Boehm e Bose (1994) } \\
\text { e Kontio (1996) }\end{array}$} & $\begin{array}{l}\text { Necessidade de diretrizes da } \\
\text { alta administração em relação a } \\
\text { análise de riscos. }\end{array}$ & $\begin{array}{l}\text { Como se pode perceber o apoio da alta- } \\
\text { administração? Qual influência no GR? }\end{array}$ & - & $X$ & $X$ \\
\hline \multirow{2}{*}{\multicolumn{3}{|c|}{$\begin{array}{l}\text { Galway } \\
(2004)\end{array}$}} & Precisão. & $\begin{array}{l}\text { Como a análise de riscos forneceu } \\
\text { precisão ao prazo do projeto? }\end{array}$ & $X$ & $X$ & $X$ \\
\hline & & & Auxílio no processo decisório. & $\begin{array}{l}\text { Que contribuições a análise de risco } \\
\text { trouxe ao processo decisório? }\end{array}$ & $X$ & $X$ & $X$ \\
\hline \multirow{5}{*}{\multicolumn{2}{|c|}{$\begin{array}{l}\text { Galway } \\
\text { (2004) }\end{array}$}} & \multirow{5}{*}{ 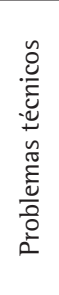 } & $\begin{array}{l}\text { Definir o nível das atividades do } \\
\text { projeto. }\end{array}$ & $\begin{array}{l}\text { Como foi definido o nível das atividades } \\
\text { do projeto? }\end{array}$ & $X$ & $X$ & $X$ \\
\hline & & & Definir as probabilidades. & Como foram definidas as probabilidades? & $X$ & $X$ & - \\
\hline & & & $\begin{array}{l}\text { Desprezar as correlações entre } \\
\text { as atividades. }\end{array}$ & $\begin{array}{l}\text { Como foi considerada a relação entre as } \\
\text { atividades? }\end{array}$ & $X$ & $X$ & - \\
\hline & & & $\begin{array}{l}\text { lgnorar os efeitos dashabilidades } \\
\text { do gerente de projeto. }\end{array}$ & $\begin{array}{l}\text { Como foram incorporadas as habilidades } \\
\text { do gerente de projeto? }\end{array}$ & $X$ & $X$ & $X$ \\
\hline & & & Dados nunca são suficientes. & Fale-me sobre os dados utilizados? & $X$ & $X$ & $X$ \\
\hline
\end{tabular}


desenvolvimento de produtos; inexistência de especialistas com experiência em gerenciamento de projetos, maximizando assim a ampla identificação de riscos, conforme preconizado por Maytorena et al. (2007), e facilidade de acesso aos registros e aos colaboradores envolvidos na elaboração do PAPP.

0 estudo foi realizado em uma empresa multinacional de autopeças de pequeno porte, que atendeu a todos os critérios pré-definidos. Os principais clientes da empresa são montadoras como Ford, Volkswagen e General Motors. Em média, cerca de três novos produtos são desenvolvidos por ano, com tendência de crescimento, sendo o processo APQP evidenciado por meio da elaboração e da submissão do PAPP. 0 principal problema do processo de desenvolvimento de produtos da empresa é o não cumprimento do prazo, que acaba sendo cumprido à custa de elevado stress e consumo extra de recursos.

0 produto final é standard, tendo apenas algumas poucas características alteradas entre um novo produto e outro; note-se que a manufatura de todos os produtos passa pelos mesmos processos e equipamentos. A Figura 1 descreve o processo de desenvolvimento de produto da empresa, comparando-o com o APQP e destacando os registros gerados.

Não foi dada ênfase nos custos devido ao produto não possuir custos elevados e o problema premente do PDP ser o não cumprimento dos prazos.

A equipe do projeto é constituída pelo gerente da planta (gerente do projeto), pelo pesquisador, pelo engenheiro de produto e pelo supervisor de produção.

A implantação do gerenciamento de riscos ocorreu por meio de reuniões com a equipe de projeto, sendo programada para cada etapa do planejamento uma reunião específica. Os dados coletados ao longo da pesquisa seguem o planejamento descrito no Quadro 3. As etapas prescritas no PMBoK (PMI, 2004) e implementadas foram:

\subsection{Planejamento e gerenciamento de riscos}

As atividades a serem desenvolvidas na execução do PAPP foram identificadas e descritas por meio da Work Breakdown Structure (WBS).

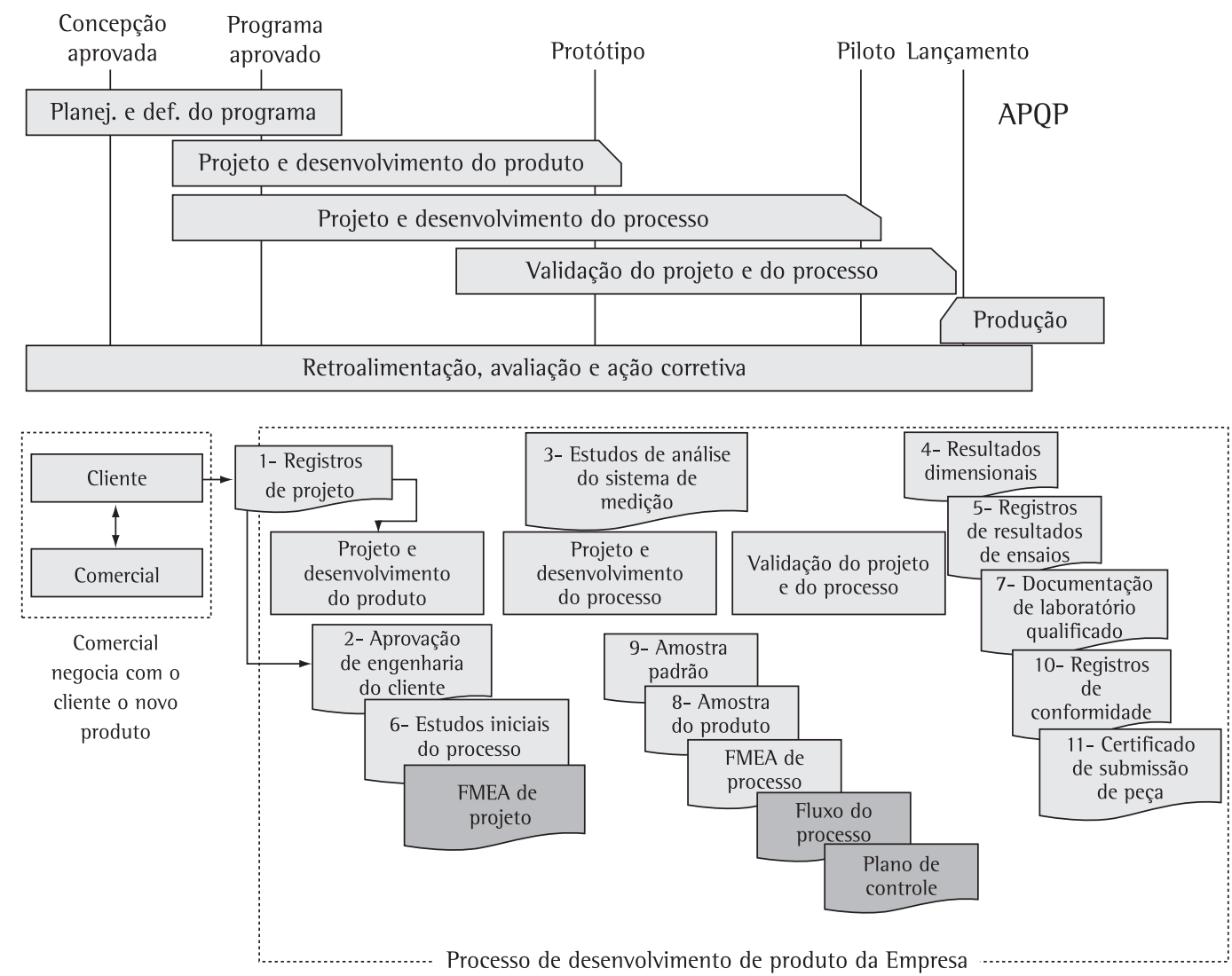

Figura 1. Processo de desenvolvimento de produtos da empresa estudada. 
Para confecção da WBS, foi utilizada a análise documental, os conhecimentos do pesquisador e a posterior validação pelo gerente da planta. Esta etapa foi realizada com rapidez, devido às semelhanças entre os projetos de desenvolvimento de produto e à baixa complexidade do projeto.

\subsection{Identificação de riscos}

Os riscos foram identificados por meio da análise de cada etapa da WBS do PDP. As técnicas utilizadas limitaram-se à revisão de documentação (que possuía poucos dados) e o brainstorming (no qual a maioria dos riscos foi identificada). Posteriormente, os riscos identificados foram classificados em qualitativos e quantitativos (Quadro 4). A participação de toda a equipe de projeto e o clima descontraído favoreceram a identificação dos riscos, porém as diretrizes para a seleção dos riscos identificados em cada etapa foram a factualidade e a praticidade.

Observa-se que todos os riscos qualitativos identificados restringem-se ao prazo, o que reforça a decisão de se abordarem, na análise de riscos, apenas os prazos.

Conforme decisão da equipe de projeto, algumas etapas da WBS não foram avaliadas devido ao produto ser padronizado. Dessa forma, não se consideraram os riscos envolvidos nas etapas que possuem como entregas: FMEA de projeto, diagrama do fluxo do processo, FMEA de processo e plano de controle. 0 relatório de aprovação de aparência, prescrito no PAPP, não se aplica ao produto por este não ser considerado um item de aparência.

\subsection{Análise qualitativa de riscos}

Foi analisado o impacto de cada risco identificado como qualitativo, em relação aos objetivos do projeto (custo, tempo, escopo e qualidade); posteriormente, cada risco qualitativo foi classificado em função dos objetivos do projeto: em qual desses objetivos, obteve-se o maior grau de impacto. 0 mesmo foi realizado para a probabilidade de ocorrência do risco. Por exemplo: para a entrega da atividade 'Aguardar aprovação de engenharia do cliente' (Quadro 4), foi identificado como risco qualitativo não possuir evidências das autorizações de alteração de engenharia. No custo, considerou-se o impacto deste risco como alto; no tempo, foi considerado muito alto; no escopo, médio, e na qualidade, muito alto. 0 maior impacto foi classificado pelos participantes da análise de risco como 'muito alto' para os quesitos qualidade e tempo. A probabilidade de não possuir evidências das autorizações de alteração de engenharia foi considerada pelos participantes como baixa.

Na matriz de probabilidade (Figura 2), com a probabilidade baixa e o impacto muito alto, obtém-se como orientação mitigar. Assim, é necessário o estabelecimento de ações preventivas e corretivas. Caso a orientação obtida na Figura 2 fosse aceitar, não seria necessário desenvolver ações preventivas. Esta análise completa foi registrada no formulário de análise de riscos qualitativos (Figura 3).

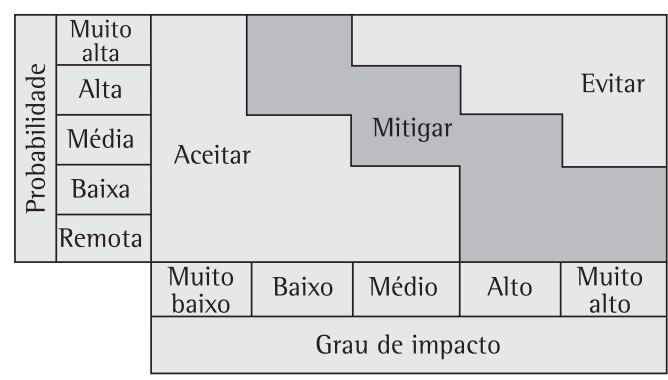

Figura 2. Matriz de probabilidade, impacto e orientação.

Quadro 4. Atividades do PAPP e seus respectivos riscos.

\begin{tabular}{|c|c|c|c|}
\hline \multirow[t]{2}{*}{ Atividade } & \multirow{2}{*}{$\begin{array}{l}\text { Entregas das atividades } \\
\text { (registros do PAPP) }\end{array}$} & \multicolumn{2}{|c|}{ Riscos } \\
\hline & & Qualitativos & Quantitativos \\
\hline $\begin{array}{l} \\
\bullet \\
\bullet\end{array}$ & $\begin{array}{l} \\
\bullet \\
\bullet\end{array}$ & $\begin{array}{l}\bullet \\
\bullet \\
\bullet\end{array}$ & $\begin{array}{l}\bullet \\
\bullet \\
\bullet\end{array}$ \\
\hline $\begin{array}{c}\text { Aguardar aprovação } \\
\text { de engenharia do cliente }\end{array}$ & $\begin{array}{c}2 \text { - Obter os documentos } \\
\text { de autorização de alteração } \\
\text { de engenharia }\end{array}$ & $\begin{array}{l}\text { Não possuir evidências } \\
\text { das autorizações de } \\
\text { alteração de engenharia }\end{array}$ & - \\
\hline $\begin{array}{ll}\bullet \\
\bullet \\
\bullet\end{array}$ & $\begin{array}{ll}\bullet \\
\bullet \\
\bullet\end{array}$ & $\begin{array}{ll}\bullet \\
\bullet \\
\bullet\end{array}$ & $\begin{array}{ll}\bullet \\
\bullet \\
\bullet\end{array}$ \\
\hline $\begin{array}{l}\text { Elaborar o certificado } \\
\text { de submissão de peça }\end{array}$ & $\begin{array}{l}12 \text { - Certificado de } \\
\text { submissão de peça }\end{array}$ & - & $\begin{array}{c}\text { Peça não submetida } \\
\text { dentro do prazo previsto }\end{array}$ \\
\hline
\end{tabular}




\begin{tabular}{|c|c|c|c|c|c|c|c|c|c|c|}
\hline \multirow{2}{*}{ Atividade } & \multirow{2}{*}{ Risco } & \multirow{2}{*}{ Probabilidade } & \multirow{2}{*}{$\begin{array}{c}\text { Grau } \\
\text { impacto }\end{array}$} & \multirow{2}{*}{$\begin{array}{l}\text { Orientação } \\
\text { intervenção }\end{array}$} & \multicolumn{3}{|c|}{ Preventiva } & \multicolumn{3}{|c|}{ Corretiva } \\
\hline & & & & & Ação & Responsável & Prazo & Ação & Responsável & Prazo \\
\hline $\begin{array}{l}\text { Estudos } \\
\text { iniciais do } \\
\text { processo }\end{array}$ & $\begin{array}{c}\text { Processos } \\
\text { fora do } \\
\text { padrão Cpk }\end{array}$ & Baixa & $\begin{array}{l}\text { Muito } \\
\text { alto }\end{array}$ & Mitigar & $\begin{array}{l}\text { Atuar no } \\
\text { controle do } \\
\text { processo } \\
\text { através CEP }\end{array}$ & Operador & Imediato & $\begin{array}{c}\text { Segregar as } \\
\text { peças e } \\
\text { inspecionar }\end{array}$ & Operador & Imediato \\
\hline $\begin{array}{l}\text { Estudos de } \\
\text { análise dos } \\
\text { sistemas de } \\
\text { medição }\end{array}$ & $\begin{array}{c}\text { Resultado } \\
\text { da análise } \\
\text { não... }\end{array}$ & Remota & $\begin{array}{l}\text { Muito } \\
\text { alto }\end{array}$ & Mitigar & $\begin{array}{c}\text { Treinar } \\
\text { operadores, } \\
\text { calibrar } \\
\text { instrumentos } \\
\text { de medição }\end{array}$ & $\begin{array}{l}\text { Depto. } \\
\text { qualidade }\end{array}$ & $\begin{array}{c}\text { De } \\
\text { acordo } \\
\text { com } \\
\text { planeja- } \\
\text { mento }\end{array}$ & $\begin{array}{c}\text { Segregar } \\
\text { peças do } \\
\text { lote analisado }\end{array}$ & Operador & Imediato \\
\hline
\end{tabular}

Figura 3. Análise de riscos quantitativos.

Observa-se que o formulário apresenta o planejamento de respostas aos riscos que consiste na orientação a ser tomada, a ação preventiva (para mitigar o risco atuando em sua causa) e a ação corretiva (o que fazer caso o risco ocorra). Como foram identificadas poucas ações, todas foram implementadas, não sendo necessário priorizá-las.

As técnicas utilizadas nesta etapa foram: avaliação de probabilidade e impacto de riscos; matriz de probabilidade e impacto; categorização de riscos, e avaliação da urgência do risco. Apenas a técnica 'avaliação da qualidade dos dados sobre riscos' não foi empregada, devido aos dados serem predominantemente verbais, oriundos da experiência em desenvolvimento de produtos da equipe de projeto. Questionamentos destes dados, inicialmente, poderiam causar reduções nos níveis de comprometimento e de participação da equipe.

\subsection{Análise quantitativa dos riscos}

0 processo de desenvolvimento de produtos ocorre de maneira sequencial, devido ao porte da empresa e à baixa complexidade do projeto, apesar da possibilidade de várias etapas do PDP poderem ser realizadas em paralelo, conforme é preconizado no APQP. Segundo o Gerente da Planta, não se realizam atividades paralelas devido aos recursos escassos.

Inicialmente, com base nos registros históricos (pouco utilizados por registrarem o prazo de entrega apenas como acordado e realizado) e na participação da equipe, foram estabelecidas as durações otimistas, prováveis e pessimistas para a realização de cada atividade (Figura 4).

A partir das durações de cada etapa, elaborou-se o sequenciamento das atividades e, posteriormente, simulou-se a duração do projeto utilizando o software@RISK (Figura 5).0 software@RISK, desenvolvido pela Paralise para realizar a análise quantitativa de riscos de projetos, fundamenta-se no algoritmo de Iman e Conover (1982), simulando variáveis dependentes e minimizando grande parte das limitações identificadas no método PERT.

Por meio da análise dos resultados obtidos na simulação, foi possível estimar a probabilidade de se atenderem os prazos. 0 prazo acordado com o cliente é de 54 dias, que tem probabilidade de 39,4\% de ser atendido, como mostra a Figura 5. Esta probabilidade foi considerada inaceitável pelos envolvidos no projeto. 0 relatório obtido na simulação também identifica a influência de cada atividade no prazo final do projeto (Figura 5). No produto estudado, a atividade mais crítica em relação a tempo é obter a documentação de laboratório especificado, pois é a que mais influencia no prazo de entrega e na sua variabilidade. Este resultado já era esperado, pois se trata da atividade que consome mais tempo no processo de desenvolvimento de produtos da empresa estudada, além de possuir a maior variabilidade absoluta (otimista 30 dias, mais provável 45 dias e pessimista 60 dias); em segundo, em relação ao tempo, figura a atividade condicionar amostra do produto (otimista dois dias, mais provável sete dias e pessimista 15 dias).

Esta etapa foi a que apresentou a maior participação dos membros da equipe durante todas as reuniões. A equipe se mostrou muito preocupada com o primerio resultado de 39\% de probabilidade de atender ao prazo. Os prazos foram repensados e discutidos, um a um, segundo orientação e coordenação do gerente do projeto. Com os dados fornecidos, foram realizadas mais três simulações, obtendo-se como probabilidade, respectivamente, $67,2 \%, 73,3 \%$ e $75,8 \%$. Os prazos fornecidos pelo laboratório foram mantidos, devido ao baixo volume de ensaios realizados pela empresa. 


\begin{tabular}{|c|c|c|c|c|}
\hline \multirow[b]{2}{*}{ Atividade } & \multirow[b]{2}{*}{ Risco } & \multicolumn{3}{|c|}{ Previsão em dias } \\
\hline & & Otimista & $\begin{array}{l}\text { Mais } \\
\text { provável }\end{array}$ & Pessimista \\
\hline Registros de projeto & $\begin{array}{l}\text { Não possuir documento de nomeação } \\
\text { do projeto dentro do prazo previsto }\end{array}$ & 1 & 2 & 3 \\
\hline $\begin{array}{c}\text { Aprovação de engenharia } \\
\text { do cliente }\end{array}$ & $\begin{array}{c}\text { Peça não aprovada dentro } \\
\text { do prazo previsto }\end{array}$ & 2 & 3 & 4 \\
\hline $\begin{array}{l}\text { Estudo de análise dos } \\
\text { sistemas de medição }\end{array}$ & $\begin{array}{l}\text { Estudo realizado fora } \\
\text { do tempo previsto }\end{array}$ & 2 & 4 & 6 \\
\hline Resultados dimensionais & $\begin{array}{l}\text { Avaliação dimensional feita } \\
\text { fora do tempo previsto }\end{array}$ & 0,5 & 4 & 6 \\
\hline Registros & $\begin{array}{l}\text { Teste não realizado } \\
\text { no tempo previsto }\end{array}$ & & & \\
\hline
\end{tabular}

Figura 4. Durações das etapas.
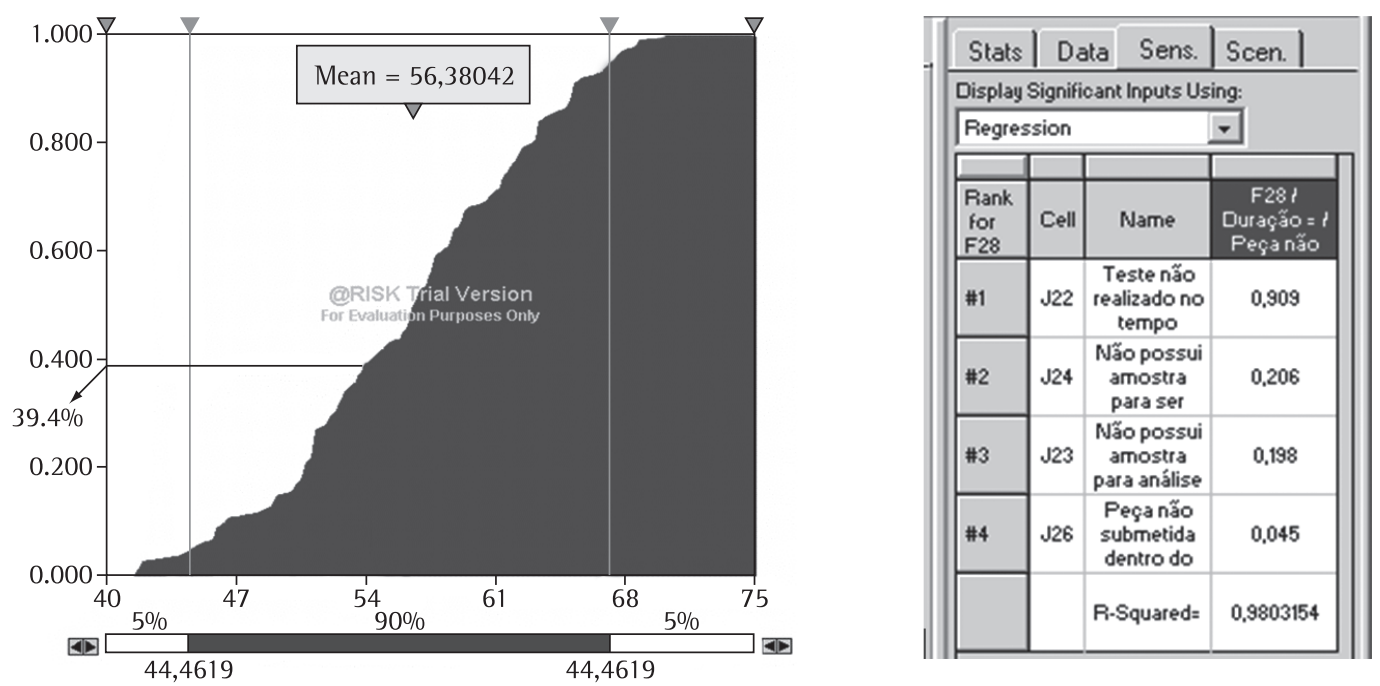

Figura 5. Tempo vs. Probabilidade e ordenação das atividades que mais impactam no prazo de entrega considerando sua variabilidade.

As técnicas de representação e coleta de dados utilizadas limitaram-se às opiniões da equipe e aos registros históricos. Técnicas de modelagem restringiram-se a modelagem e simulação aplicadas para subsidiar as decisões em relação ao prazo do projeto.

\subsection{Planejamento das respostas a riscos}

Nesta etapa, foram realizadas, simultaneamente, as análises qualitativa e quantitativa de riscos.

$\mathrm{Na}$ análise qualitativa, a adoção do formulário contribuiu para a simultaneidade, pois alguns de seus campos contemplam o estabelecimento de ações preventivas para evitar a ocorrência do risco e de ações corretivas para atuar nos riscos, caso estes ocorram (Figura 3).

$\mathrm{Na}$ análise quantitativa, redefiniram-se os prazos atribuídos às atividades e executou-se a simulação, buscando aumentar a probabilidade de atender o prazo acordado com o cliente. A existência de apenas um laboratório homologado pelo cliente para realizar os testes foi, a princípio, considerada um risco exógeno ao projeto. Foram simuladas ações sobre as atividades do projeto que estavam sob controle (internas à empresa). Em relação ao 
laboratório, foram previstas ações de tentar negociar com o laboratório a redução do prazo fornecido, monitorar o prazo fornecido pelo laboratório após o término da data otimista e negociar com o cliente a homologação de outro laboratório.

Todos os riscos identificados foram considerados ameaças, sendo a estratégia predominante a mitigação.

\subsection{Monitoramento e controle de riscos}

Os riscos qualitativos identificados foram todos implementados devido a não necessitarem de baixo aporte de recursos. A cada cinco dias, foi realizada uma reunião-relâmpago (duração máxima de $20 \mathrm{~min}$ ) de acompanhamento do projeto, com o objetivo de atualizar os prazos 'previstos vs. realizados' e, posteriormente, atualizar as análises qualitativa e quantitativa. 0 prazo do projeto passou a ser um indicador monitorado a cada cinco dias, com a incorporação da probabilidade.

As técnicas utilizadas foram a medição do desempenho técnico e, apenas visualmente no gráfico, a análise das tendências e da variação. Apesar de terem sido planejadas, as reuniões de andamento não foram realizadas. Observou-se uma contradição com a teoria que define a reavaliação dos riscos e até mesmo auditorias de riscos.

Os dados coletados ao longo do gerenciamento de riscos estão dispostos no Quadro 5, que busca responder às perguntas prescritas no planejamento da pesquisa (Quadro 3).

No desenvolvimento das etapas preconizadas pelo PMBOK para o gerenciamento de riscos, pôde ser observado que:

- Planejamento: contribuição significativa da WBS, que permite visualizar o projeto e suas etapas, bem como identificar as entregas de cada etapa (registros do PAPP).

- Identificação dos riscos: os dados são internos, oriundos da experiência dos envolvidos na equipe de projeto. Registros existentes forneceram pouca contribuição para identificação dos riscos. Os registros não foram concebidos para coletar e armazenar informações ao longo do PDP, de forma que permitissem a gestão de riscos. A triagem dos riscos concentrou-se na sua factualidade e praticidade. A classificação dos riscos identificados em qualitativos e quantitativos direcionou as abordagens posteriores.

- Análise qualitativa: realizada com facilidade, desencadeando poucas ações preventivas e corretivas.
- Análise quantitativa: o software @RISK é de fácil utilização. Foram realizadas várias simulações, exigindo dos participantes a reavaliação dos prazos fornecidos. As atitudes e orientações do gerente de projeto foram preponderantes para que esta etapa tivesse a maior participação e interesse dos envolvidos.

- Planejamento das respostas: os riscos identificados restringiram-se apenas a ameaças devido à tendência natural da maioria das pessoas em identificar com facilidade eventos que prejudicam o projeto. 0 problema de prazo da empresa e suas ações limitadas à concentração de esforços nas vésperas de entrega do produto, refletidas nas falas do gerente de projeto, contribuíram para identificar apenas ameaças.

- Monitoração dos riscos: incorporação de controle semanal do projeto, por meio de relatório e incorporação da probabilidade no índice de prazo do projeto. Foi evidente a concentração de esforços no gerenciamento de riscos nas etapas de planejamento, sendo limitada ao controle e reportados indiretamente em relatório a monitoração e o controle dos riscos.

A pesquisa-ação foi realizada durante 62 dias sem muita dificuldade, pois o pesquisador atua profissionalmente na empresa analisada. Foi percebida muita atenção dos entrevistados, pois o gerenciamento de riscos apresentou-se como oportuno para minimizar as ações corretivas comuns para que o PDP atendesse os prazos exigidos. Devido à análise de riscos, o projeto analisado foi desenvolvido dentro do prazo, tal como os outros, trazendo como vantagem a inexistência de esforços concentrados próximos à data de entrega. Segundo um dos membros da equipe, "quando cada um faz a sua parte, tudo fica mais fácil. Acho que o gerenciamento de riscos melhorou nossa comunicação." Toda análise foi validada com a equipe envolvida no PDP.

0 pequeno porte da empresa, que possui uma equipe reduzida, propicia agilidade no PDP e maior ênfase no conhecimento tácito, predominando assim a comunicação direta informal. Consequentemente, a ênfase de dados foi limitada ao conhecimento tácito dos envolvidos no PDP.

A aceitação, o interesse pela análise qualitativa de riscos e o pequeno interesse pela análise quantitativa são consequências da formação em ciências exatas de todos os membros da equipe de projetos. A inexistência de conhecimento e experiência em gerenciamento de riscos não interferiu na implementação do mesmo. Foi preponderante a posição hierárquica e o papel do gerente de projeto, que evidenciou as diretrizes da alta administração. 
Quadro 5. Resultados obtidos e análises.

\begin{tabular}{|c|c|}
\hline $\begin{array}{l}\text { Conclusões dos } \\
\text { pesquisadores }\end{array}$ & Resultados obtidos e análises \\
\hline $\begin{array}{l}\text { Buscar informações } \\
\text { em fontes seguras, } \\
\text { externas ao grupo }\end{array}$ & $\begin{array}{l}\text { Não ocorreu. As informações de prazos foram obtidas com facilidade. A equipe dispunha dos } \\
\text { dados necessários, fundamentados, principalmente, na senioridade na empresa, na experiência no } \\
\text { PDP e na restrição de tempo. Foi consultado o laboratório homologado pelo cliente em relação } \\
\text { ao prazo necessário para realização do ensaio. Verificou-se certa contrariedade da equipe para } \\
\text { buscar informações históricas de outros projetos. A principal alegação foi que esta seria inócua, } \\
\text { devido à inexistência de dados nesses registros. }\end{array}$ \\
\hline $\begin{array}{l}\text { Estilo de feedback na } \\
\text { busca de informações }\end{array}$ & $\begin{array}{l}\text { Presente e relevante. A integração dos membros da equipe e o perfil do gerente de projeto } \\
\text { permitiram uma ampla abertura na coleta das informações relativas ao risco, com grande } \\
\text { predominância de dados verbais, baseados na experiência dos envolvidos. }\end{array}$ \\
\hline $\begin{array}{l}\text { Nível de educação } \\
\text { formal }\end{array}$ & $\begin{array}{l}\text { Foi preponderante a formação em ciências exatas dos participantes para a percepção positiva } \\
\text { em relação à análise quantitativa. Segundo a ficha do funcionário, a equipe é formada por dois } \\
\text { engenheiros, um graduando em engenharia e um técnico mecânico. }\end{array}$ \\
\hline $\begin{array}{l}\text { Treinamento em } \\
\text { gerenciamento } \\
\text { de risco }\end{array}$ & $\begin{array}{l}\text { Nenhuma capacitação específica em gerenciamento de riscos. Restrito apenas ao pesquisador que } \\
\text { havia realizado um curso de extensão em gerenciamento de projetos. A capacitação foi realizada } \\
\text { ao longo do projeto, no qual a teoria era rapidamente aplicada ou apresentada. A aplicação do } \\
\text { gerenciamento de riscos foi registrada como treinamento. }\end{array}$ \\
\hline $\begin{array}{l}\text { Experiência do gerente } \\
\text { de projeto }\end{array}$ & $\begin{array}{l}\text { Experiência de dez anos de empresa, dominando todos os processos, altamente focado nos } \\
\text { resultados, sem conhecimento conceitual de gerenciamento de projetos. Como o gerente do } \\
\text { projeto é o representante da administração na fábrica (mais alto cargo), sua participação foi } \\
\text { fundamental para o envolvimento dos demais participantes e na posterior implantação das ações } \\
\text { preventivas estabelecidas. }\end{array}$ \\
\hline $\begin{array}{l}\text { Maioria dos esforços } \\
\text { alocados nas etapas } \\
\text { de planejamento, } \\
\text { sendo deficientes a } \\
\text { monitoração e o } \\
\quad \text { controle }\end{array}$ & $\begin{array}{l}\text { A maioria dos esforços foi alocada nas etapas de planejamento, no qual foi realizado } \\
\text { o gerenciamento dos riscos com a participação conjunta de toda equipe (face a face). } \\
\text { Posteriormente, as ações foram acompanhadas pelo pesquisador e reportadas aos envolvidos } \\
\text { através de relatórios por e-mail. Informações adicionais eram obtidas pelo pesquisador } \\
\text { informalmente, de maneira verbal direta (face a face) ou por e-mail. Não se realizaram as } \\
\text { reuniões previstas a cada cinco dias. Segundo o gerente do projeto, "o projeto estava atendendo } \\
\text { os prazos ... as reuniões planejadas não precisaram ser realizadas". }\end{array}$ \\
\hline $\begin{array}{l}\text { Necessidade de diretrizes } \\
\text { da alta administração } \\
\text { em relação à } \\
\text { análise de riscos }\end{array}$ & $\begin{array}{l}\text { O representante da alta administração era o gerente do projeto, sendo fundamental para obter } \\
\text { o comprometimento e envolvimento dos demais membros da equipe. Ele foi fundamental } \\
\text { nas etapas do planejamento (participação de toda equipe nas reuniões), monitoração e controle } \\
\text { (interesse nos resultados teve efeito motivador). }\end{array}$ \\
\hline Precisão & $\begin{array}{l}\text { A análise de riscos quantitativa foi a que mais trouxe contribuição para o PDP (resposta } \\
\text { unânime de toda equipe). As simulações permitiram maior precisão nos prazos fornecidos. A } \\
\text { participação criou compromisso dos envolvidos com os prazos fornecidos. Segundo o gerente } \\
\text { do projeto, "enquanto não tivermos pelo menos } 90 \% \text { de probabilidade de entregarmos no } \\
\text { prazo eu não vou ficar satisfeito". }\end{array}$ \\
\hline $\begin{array}{l}\text { Auxílio no processo } \\
\text { decisório }\end{array}$ & $\begin{array}{l}\text { Várias ações foram implementadas, sendo que a maioria delas foi identificada no início do } \\
\text { projeto. Na etapa de monitoração e controle, as ações restringiram-se ao cumprimento dos } \\
\text { prazos acordados e a monitoração das análises realizadas pelo laboratório. A duração do projeto } \\
\text { limitou a aplicação do gerenciamento de risco nas fases de planejamento e controle do projeto. } \\
\text { A teoria pressupõe o gerenciamento contínuo dos riscos ao longo da execução do projeto, o que } \\
\text { não pôde ser realizado. As lições aprendidas limitaram-se à incorporação da análise quantitativa } \\
\text { aos projetos do PDP. Nas palavras do gerente do projeto, "gostei de incorporar probabilidade ao } \\
\text { prazo do projeto que já monitorávamos ... vamos fazer isso nos outros projetos". }\end{array}$ \\
\hline $\begin{array}{l}\text { Definir o nível das } \\
\text { atividades do projeto }\end{array}$ & $\begin{array}{l}\text { Não foi observada nenhuma dificuldade, devido ao número de atividades do projeto, além } \\
\text { do PDP ser executado de maneira sistematizada (certificação ISO TS 16949). Segundo um dos } \\
\text { membros da equipe, "as atividades já estão definidas... isso é fácil". }\end{array}$ \\
\hline $\begin{array}{l}\text { Definir as } \\
\text { probabilidades }\end{array}$ & $\begin{array}{l}\text { Relevante o fornecimento preciso, compartilhado em reunião, com análise crítica de todos da } \\
\text { equipe. Primeiramente, foram fornecidos prazos otimistas, mais prováveis e pessimistas, de maneira } \\
\text { rápida e com pouca discussão, sendo, posteriormente, discutidos e repensados através de simulações. }\end{array}$ \\
\hline $\begin{array}{l}\text { Desprezar correlações } \\
\text { entre as atividades }\end{array}$ & $\begin{array}{l}\text { Não foi considerada relação entre as atividades, além das estabelecidas no sequenciamento } \\
\text { devido à baixa complexidade do projeto e ao PDP ser sequencial. }\end{array}$ \\
\hline $\begin{array}{l}\text { lgnorar os efeitos das } \\
\text { habilidades do gerente } \\
\text { de projeto }\end{array}$ & $\begin{array}{l}\text { As habilidades do gerente de projeto não foram consideradas de maneira premeditada e sim } \\
\text { naturalmente. A equipe de projeto trabalha junto e interage diretamente há bastante tempo, } \\
\text { gerando conhecimento mútuo. Assim, a equipe já conhecia previamente as habilidades do gerente } \\
\text { de projeto e suas atitudes ao longo do projeto. }\end{array}$ \\
\hline $\begin{array}{l}\text { Dados nunca são } \\
\text { suficientes }\end{array}$ & $\begin{array}{l}\text { Não foi evidenciada, devido à baixa complexidade do projeto, a existência de um PDP padronizado, } \\
\text { o porte da empresa, a representatividade dos membros da equipe gestores das áreas envolvidas no } \\
\text { PDP. } 0 \text { problema identificado restringiu-se, inicialmente, à precisão dos dados. }\end{array}$ \\
\hline
\end{tabular}


Neste projeto, não foi necessária a incorporação no orçamento de uma reserva contingencial para minimizar efeitos de possíveis eventos negativos de riscos. 0 fato de a empresa não trabalhar com seus projetos da maneira preconizada pelo PMBoK a influenciou na aplicação do gerenciamento de riscos. Assim, a implementação do gerenciamento de riscos segundo o PMBoK propiciou aos participantes: um melhor detalhamento do projeto através da WBS; o estabelecimento realista e refinado dos prazos; o comprometimento com os resultados; a identificação das etapas críticas do projeto; o controle sistemático do projeto; a transferência do conhecimento tácito para explícito através dos registros utilizados no gerenciamento de riscos, e a incorporação e a socialização das necessidades específicas das áreas envolvidas em relação ao projeto por meio das reuniões de análise de risco.

\section{Conclusões e recomendações}

0 projeto, selecionado como objeto de estudo do presente trabalho, apresentava baixo nível de complexidade e desenvolvimento periódico, propiciando assim conhecimento tácito à equipe envolvida no PDP, refletido ao longo da implantação do gerenciamento de riscos. Destaque-se que as conclusões descritas se limitam ao estudo realizado, mas fornecem orientações científicas para outras pesquisas e práticas para as empresas que pretendem implementar o gerenciamento de riscos no PDP.

0 PDP, segundo a abordagem pelo APQP, contribui para a implementação do gerenciamento de riscos, por definir explicitamente as entregas mínimas no PAPP.

A principal contribuição do gerenciamento de riscos no PDP observada no presente trabalho foi a incorporação do monitoramento contínuo do projeto, centrado em indicadores (prazo e custos) com as respectivas probabilidades de atendimento.

0 gerenciamento de riscos tende a concentrar os maiores esforços nas etapas de planejamento em relação às etapas de controle, pois a execução do projeto passa a ser prioritário. Desde que o projeto não necessite de ações corretivas, a equipe restringe-se ao controle dos riscos através de relatórios periódicos e comunicação informal.

A incorporação do gerenciamento de riscos no PDP contribui para o processo decisório, principalmente nas etapas de análise de riscos qualitativos e de planejamento de respostas aos riscos, fornecendo maior precisão quanto aos prazos e à identificação das atividades críticas. Através do processo participativo, realizado por meio de reuniões planejadas, ocorreram reflexões conjuntas dos membros da equipe ao longo das simulações, resultando em maior exatidão dos prazos, data planejada para início e término das atividades, bem como a redução da variabilidade. 0 processo participativo da pesquisa evidenciou o comprometimento da equipe.

Os fatores que se destacaram para se obter a precisão dos resultados foram: a formação de uma equipe representativa e experiente do PDP; a discussão coletiva dos prazos por meio da participação ativa da equipe, resultando no comprometimento dos integrantes da mesma; o papel do gerente do projeto no planejamento e na condução das reuniões, propiciando um adequado feedback entre os participantes da equipe, e a existência de evidências objetivas do apoio da alta administração.

A formação da equipe influenciou no gerenciamento de riscos, sendo preponderante na percepção dos riscos a formação educacional. Porém, esta pode limitar a identificação de outros riscos devido ao efeito pernicioso da experiência adquirida ao longo do desenvolvimento de projetos similares.

Recomenda-se a incorporação mais detalhada do gerenciamento de riscos no APQP, uma vez que a pesquisa realizada sugere que o mesmo contribuiu no atendimento dos prazos e na qualidade intrínseca do produto. Da mesma forma, recomenda-se que a empresa estudada incorpore em seus projetos a sistemática preconizada pelo PMBoK. Sugerem-se ainda, como propostas para futuros trabalhos, uma análise acerca do efeito do gerenciamento de riscos no sucesso de um novo produto desenvolvido e um estudo que verifique se a avaliação qualitativa do risco apresenta maior assertividade do que a avaliação quantitativa do risco.

Para continuidade desta pesquisa, recomenda-se sua replicação em projetos complexos, a análise da integração do gerenciamento de riscos com o Earned Value e o aprofundamento de estudos que abordem as diferenças entre a ênfase nas etapas de planejamento e de controle.

\section{Referências}

ALBENY, R. M. Análise da importância da mensuração e controle do valor da exposição a riscos em projetos de desenvolvimento de produtos complexos. 2007. Dissertação (Mestrado) - Universidade de São Paulo, São Paulo.

ALENCAR, A. J.; SCHMITZ, E. A. Análise de risco em gerência de projetos. 1 ed. Rio de Janeiro: Brasport, 2006.

ARTTO, K. A. Fifteen years of project risk management applications: where are we going?. In: ARTTO, K. A.; KAHKONEN, K. (Eds.). Managing Risks in Projects. London: E\&FN SPON, 1997. p. 3-14.

BASKERVILLE, R.; STAGE, J. Controlling prototype development through risk analysis. MSI Quarterly, v. 20, n. 4, p. 481-504, 1996.

BLAU, G. E. et al. Risk management in the development of new products in highly regulated industries. Computers and Chemical Engineering, v. 24, n. 1, p. 659-664, 2000. 
BOEHM, B. W.; BOSE, P. A. Collaborative spiral software process model based on theory. In: International Conference on the Software Process, 3, 1994. Proceedings... Washington, DC: 1EEE Computer Society, 1994.

BRIGHENT1 Jr., D. Proposta para o gerenciamento de risco em projetos de desenvolvimento de software - pesquisa-ação na Ford Motor Company Brasil. 2005. Dissertação (Mestrado em Engenharia de Produção) - Universidade Federal de Engenharia de ltajubá, Itajubá.

BROTHERS, M. A.; FAYSSAL, M. S. Engineering management capstone project EM 697: compare and contrast risk management implementation at NASA and the US Army. In: INTERNATIONAL CONFERENCE ON INDUSTRY, ENGINEERING AND MANAGEMENT SYSTEMS, 2002, Cocoa Beach, Flórida. CD-ROM.

CHAMBERLAIN, S.; MODARRES, M. Compressed natural gas bus safety: a quantitative risk assessment. Risk Analysis, v. 25, n. 2, p. 377-387, 2005.

FERREIRA, V. V.; OGLIARI, A. Diretrizes para a concepção de uma metodologia de gerenciamento de riscos para o processo de projeto de produtos. In: CONGRESSO BRASILEIRO DE GESTÃO DE DESENVOLVIMENTO DE PRODUTO - CBGDP, 5, 2005, Curitiba.

GALWAY, L. A. Quantitative risk analysis for complex projects a critical review. RAN Corporation, 2004.

HUCHZERMEIER, A.; LOCH, C. H. Project management under risk: using the real options approach to evaluate flexibility in R\&D. Management Science, v. 47, n. 1, p. 85-101, 2001.

IMAN, R. L.; CONOVER, W. J. A distribution-free approach to inducing rank correlations among input variables. Communications in Statistics, v. 11, n. 3, p. 311-334, 1982.

INSTITUTO DA QUALIDADE AUTOMOTIVA - 1QA. Planejamento avançado da qualidade do produto e plano de controle (APQP). Manual de Referência do Sistema da Qualidade QS 9000, 1997. São Paulo, 1997.

INSTITUTO DA QUALIDADE AUTOMOTIVA - 1QA. Processo de aprovação de peça de produção (PPAP). Manual de Referência do Sistema da Qualidade QS 9000, 1999. São Paulo, 1999.

KONTIO, J. The riskit method for software risk management, version 1.00, CS-TR-3782 / UMIACSTR- 97-38. College Park, MD: University of Maryland, 1997. Computer Science Technical Reports.

LYONS, T.; SKITMORE, M. Project risk management in the Queensland engineering construction industry: a survey. International Journal of Project Management, v. 22, p. 51-61, 2004.

MAHADEVAN, S.; SMITH, N.; ZANG, T. A. System Risk Assessment and Allocation in Conceptual Design. NASA/CR-2003-212162. Hampton, VA: Langley Research Center, 2003.

MAYTORENA, E. et al. The influence of experience and information search styles on project risk identification performance. IEEE Transactions on Engineering Management, v. 54, п. 2, p. 315-326, 2007.
MILLER, R.; LESSARD, D. Understanding and managing risks in large engineering projects. International Journal of Project Management, v. 19, n. 1, p. 437-443, 2001.

NAKASHIMA, D. T. V.; CARVALHO, M. M. Identificação de riscos em projetos de Tl. In: Encontro nacional de engenharia de produção, 24, 2004, Florianópolis.

PROJECT MANAGEMENT 1NSTITUTE - PMI. Um guia do conjunto de conhecimentos em gerenciamento de projetos (Guia PMBOK ${ }^{\circledR}$ ). 3 ed. EUA, 2004.

RAZ, T.; MICHAEL, E. Use and benefits of tools for project risk management. International Journal of Project Management, v. 19, p. 9-17, 1999.

ROVAl, R. L. Modelo para gestão de riscos em projetos: estudo de múltiplos casos. 2005. Tese (Doutorado) - Escola Politécnica da Universidade de São Paulo, São Paulo.

SCHUYLER, J. R. Risk and decision analysis in projects. 2 ed. Newtown Square: PMl, 2001.

SEGISMUNDO, A.; MIGUEL, P. A. C. Risk management in the development of new products: A review and classification of the literature. Product: Management \& Development, v. 6, n. 1, p. 45-51, 2008.

SMITH, P. G.; MERRITT, G. M. Proactive risk management: controlling uncertainty in product development. New York: Productivity Press, 2002.

TH10llENT, M. Metodologia da pesquisa-ação. São Paulo: Cortez: Autores Associados, 1986.

TRAMMELL, S. R.; LORENZO, D. K.; DAVIS, B. J. Integrated hazards analysis: using the strengths of multiple methods to maximize effectiveness. Professional Safety, v. 49, n. 5, p. 29-37, 2004.

VIEIRA, V. M. G. A efetividade do planejamento avançado da qualidade do produto como ferramenta para prevenção de defeitos de qualidade inicial no lançamento de novos produtos. 2007. Dissertação (Mestrado em Engenharia Automotiva) - Escola Politécnica da Universidade de São Paulo, São Paulo.

VOETSCH, R. J. The current state of project risk management practices among risk sensitive project management professionals. 2004. Tese (Doutorado) - The George Washington University.

\section{Agradecimentos}

À CAPES (Programa Pró-Engenharias - processo PE024/2008; PRODOC - 102059), à FAPEMIG (projetos 011/07 - TEC APQ 6412-6.01/07; EDT-538/07; TEC-PPM00043-08) e a CNPq pela bolsa de Mestrado. Agradecimentos especiais à empresa (principalmente àqueles envolvidos na presente pesquisa) e aos entrevistados. Agradecemos também aos referees que contribuíram consideravelmente para a melhoria deste trabalho.

\title{
Application of risk management in the product development process of auto parts companies
}

\begin{abstract}
This research analyzes the incorporation of risk management in the product development process (PDP) in auto parts companies, based on Advanced Product and Quality Planning (APQP), and emphasizes the delivery of project development proposed by the Production Part Approval Process (PPAP) and conducts a review of the literature, establishing the theoretical foundations for its development. The research method used was action research, where data were collected through documentary analysis, interviews and researchers' observations. The incorporation of risk management contributes to the PDP-making processes, especially in the stages of qualitative risk analysis and planning of responses to risk, providing greater accuracy of the time and identification of critical activities. The factors that emerged as most important for guaranteeing the accuracy of the results are: team building; collective discussion of deadlines set, resulting in commitment; the role of project manager, providing feedback from the participants; the existence of objective evidence in support of senior management. It follows that team-building impacts on risk management, as in the perceived risk to ongoing education.
\end{abstract}

Keywords

Project management. Risk management. Product development. APQP. PPAP. 